\title{
Impressão 3D na moda: desafios e reflexões
}

Marcela Luíza Calixto;

Maria Adircila Starling Sobreira

resumo:

Como força motriz da Quarta Revolução Industrial, a Impressão 3D é constantemente enaltecida pelas contribuições inovadoras proporcionadas ao processo produtivo, no entanto, os impactos dessa tecnologia ainda são pouco avaliados e discutidos. Nesse sentido, com o intuito de analisar, refletir e vislumbrar os possíveis efeitos dessa técnica no segmento da Moda, fez-se uma pesquisa bibliográfica de caráter exploratório com o objetivo de contextualizar a técnica no setor, bem como discutir alguns de seus desdobramentos sociais, mercadológicos, sustentáveis e legais.

\section{palavras-chave:}

Moda; Impressão 3D; Impactos sociais; Sustentabilidade; Direitos autorais 


\section{Introdução}

A impressão 3D é considerada um dos pilares da indústria 4.0, ao lado da realidade aumentada, internet das coisas, robôs autônomos, segurança cibernética, armazenamento de dados na nuvem, integração horizontal e vertical, simulação e big data (THE BOSTON CONSULTING GROUP, 2015). É uma tecnologia insensível a quantidade e complexidade (SANTOS et al., 2018), o que possibilita produção unitária de produtos e, como consequência, alta customização de projetos com maior liberdade de design.

Nesse contexto, a impressão 3D está impulsionando a transição da produção em massa para a personalização em massa. Além disso, favorece uma redução da localização da produção, na medida em que se torna mais vantajoso produzir perto de casa do que em países com mão de obra barata (MARTINS, 2017; SANTOS et al., 2018). Desde o surgimento, na década oitenta, o sistema de impressão tridimensional tem conquistado cada vez mais espaço no mercado. Inicialmente desenvolvido como um processo de prototipagem rápida, essa tecnologia é aplicada na contemporaneidade em diversificadas áreas (MONTEIRO, 2015).

Com o funcionamento semelhante às impressoras convencionais, a 3D substitui os jatos de tinta por materiais alternativos como plástico, metal e resina formando, assim, camada por camada, um objeto. Cada máquina 3D adapta-se a uma finalidade, necessitando, desse modo, de processos e materiais adequados.

Imprimir réplicas reais de comida, tecido humano, órgãos, casas, produtos esportivos, próteses, pode parecer algo muito distante da realidade, mas, já são possíveis a partir de diferentes processos de manufatura aditiva, que até pouco tempo, eram restritos às grandes indústrias (CONCEIÇÃO e SANTOS, 2017, n.p).

Monteiro (2015) e Conceição e Santos (2017) salientam que, dado a usabilidade do método, essa inovação tecnológica tem sido empregada no design, na medicina, engenharia e moda, permitindo novas aplicações e criações, tornando as produções verdadeiros experimentos, possibilitando também que os consumidores tornem-se colaboradores ou até mesmo criadores de produtos.

A fabricação digital, traz uma nova perspectiva com relação ao design, processo extremamente flexível, estabelece uma nova relação entre quem cria e quem usa o produto. Permite, que o objeto seja produzido de acordo com o gosto pessoal ou necessidade do usuário; ou, até mesmo, pelo próprio usuário (CONCEIÇÃO e SANTOS, 2017, n.p).

No cenário da moda a técnica possibilitou o rompimento de barreiras entre arte e ciência, sendo palco para revoluções. Iris Van Herpen se destaca no ramo da impressão 3D nas passarelas por constantemente unir luxo e tecnologia, abordando temáticas que buscam romper paradigmas. Gomes (2015, p. 15) aborda que "A Impressão 3D e a Moda reuniram-se apenas recentemente, mas já se verificou que a sua aliança terá grande utilidade e novidade no mundo da moda, tornando-se um caminho promissor".

Em contrapartida aos benefícios trazidos pelo processo, o presente artigo analisou, a partir da revisão bibliográfica, as possíveis adversidades existentes no processo e uso das impressoras 3D. Assim como Monteiro (2015) evidencia, mesmo com a grande popularização dos equipamentos e recursos da produção 3D, as reais consequências que essas transformações trarão para a sociedade contemporânea ainda são desconhecidas.

\section{Contextualização}

A manufatura aditiva, também conhecida como impressão 3D tem origem em meados de 1980, sendo inicialmente utilizada como uma forma de prototipagem rápida para teste de produtos industriais, 
surgindo na tentativa do Dr. Hideo Kodama registrar a técnica. No entanto, devido a alguns empecilhos, a averbação não foi efetivada sendo, posteriormente, patenteada no ano de 1986 por Charles Hull, inventor da impressora 3D em 1983, o qual viria se tornar cofundador, vice-presidente executivo e diretor de tecnologia da 3D Systems, empresa que oferta dispositivos e materiais relacionados a impressão 3D (KUHN e MINUZZI, 2015).

Sendo assim, o processo de impressão consiste em um desenho 3D digital feito em computador com softwares do tipo Computer Aided Design (CAD - Desenho assistido por computador), os quais auxiliam o desenvolvimento de desenhos técnicos e modelos 3D digitais, em que os esboços podem também ser modelos prontos existentes em sites. Em seguida, o projeto é enviado para impressora no qual o material adequado é escolhido e, consequentemente, a impressão começará a ser feita por meio da sobreposição de camadas de matéria-prima até que o objeto seja formado por completo.

De acordo com Volpato (2007) a prototipagem é a fase primordial no desenvolvimento do produto, possibilitando a conferência antes da produção definitiva ser concluída. Com isso, a técnica tem se tornado um grande investimento para micro e pequenas empresas, sendo constantemente utilizada em projetos arquitetônicos para oferecer plantas, uma vez que a prototipagem diminui as chances de erro e desperdícios de matéria-prima, possibilitando também a customização em massa (MOREIRA, 2011).

Além disso, sendo os arquivos digitais, não há limitações a respeito do armazenamento físico dos produtos, com isso, apesar do destaque da tecnologia estar voltada para a prototipagem, o método também é empregado para fabricação de produtos finais, sendo aplicado em distintas esferas como a da medicina, robótica, educação, cinema, e design (ASSIS, 2018).

Cada vez mais a utilização das impressoras tridimensionais tem se tornado uma realidade no cotidiano de empresas, marcas e até mesmo consumidores. A oportunidade de personalização e customização em massa faz com que pessoas tornem-se verdadeiros agentes no processo produtivo, impulsionando o movimento Maker. Derivado da cultura Do It Yourself (DIY) - Faça Você Mesmo, consiste na prática de autossuficiência produtiva baseada na distribuição de conhecimento (HESS, 2020).

Viabilizada pelos meios digitais, permite que pessoas desenvolvam projetos sem a dependência de uma produção industrial, grandes maquinários ou a ajuda de um profissional especializado na área, sendo consideradas as ferramentas, especificidades e custos acessíveis a esses indivíduos (HESS, 2020).

\subsection{Aplicações da tecnologia de impressão 3D na Moda}

Kuhn e Minuzzi (2015, n.p) enfatizam que "a impressão 3D abriu novas fronteiras para criações no setor do Fashion Design, visto que essa tecnologia permite uma nova transgressão de limites técnicos anteriormente indisponíveis." Com isso, a introdução da impressão 3D no setor do vestuário, principalmente feminino, no início dos anos 2000, possibilitou a criação de verdadeiras obras de arte sem a necessidade dos tecidos convencionais e materiais habituais, abrindo espaço para a arte e o design se fundirem.

No âmbito da indústria de moda, Janne Kyttanen, designer conceitual finlandês, se destaca ao ser o primeiro a incorporar a manufatura aditiva no setor de moda. Desenvolvido em parceria com um engenheiro por meio da técnica de Sinterização Seletiva a Laser (SLS), método o qual um laser funde o material em pó até a formação completa do objeto, o primeiro modelo funcional de vestuário foi denominado de Black Drape Dress (CONCEIÇÃO e SANTOS, 2017; KUHN e MINUZZI, 2015), exposto logo abaixo (figura 1). 
Figura 1 - Black Draped Dress de Janne Kytannen
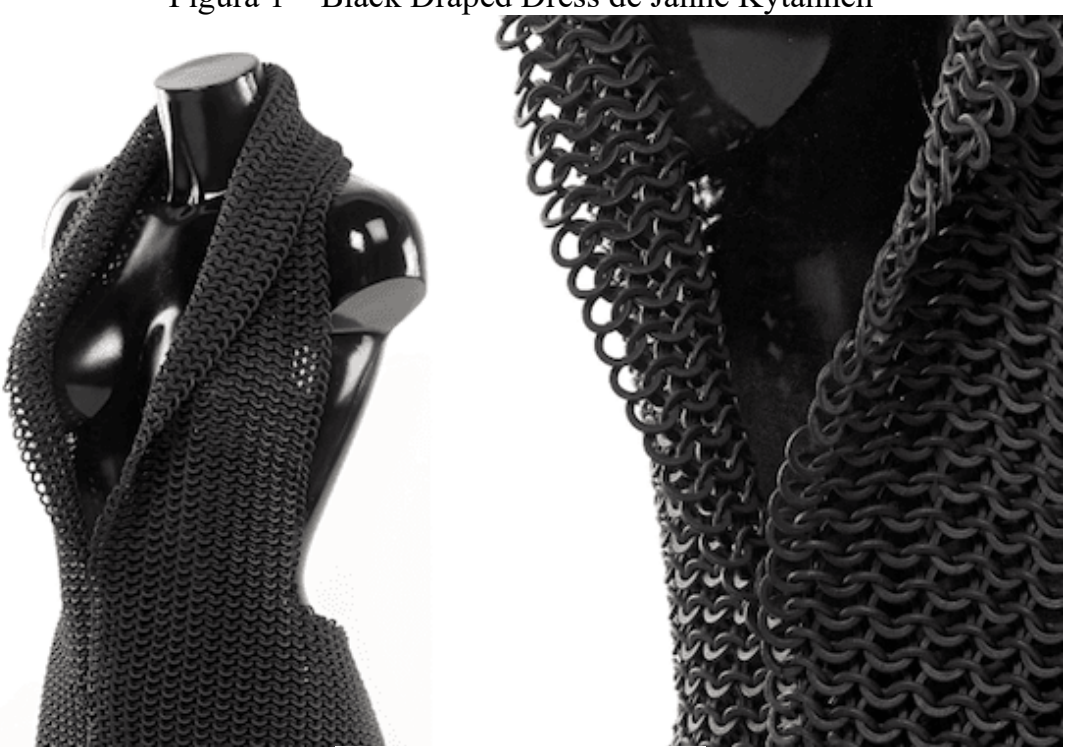

Fonte: Robyn Reiter, 2013

Como pioneira na área, tal peça representa um marco da revolução tecnológica na moda, sendo constantemente reproduzida por outros estilistas. Devido a sua importância, compôs o acervo do The Museum of Modern Art- Museu de Arte Moderna (MoMA) em Nova Iorque.

Kyttanen também se distingue por desenvolver uma linha de sapatos (figura 2) a partir do método, proporcionando que o consumidor escolha entre a peça pronta ou o arquivo digital, disponibilizado gratuitamente, para impressão doméstica. A escolha da cor, do tamanho, modelo e alguns detalhes são critérios dos clientes, sendo quatro os estilos disponibilizados (VICENTE, 2016).

Essa interação entre designer e cliente também se estabelece como um processo de marketing, que visa atender e entender as necessidades e os desejos dos consumidores, buscando sempre oferecer o melhor produto final de acordo as características do segmento de mercado (KOTLER e KELLER, 2012)

Junior e Castillo $(2014$, p. 9) ressaltam “[...] que o designer não estará mais focado apenas no produto, mas na solução de um determinado problema de modo a satisfazer as necessidades dos usuários". Isto é, os desejos são moldados pela sociedade em que o indivíduo pertence, entender o consumidor por meio desse contato faz com que a produção alcance o público alvo estabelecido pela marca, cativando-o progressivamente.

Figura 2 - Sapatos desenvolvidos pelo método 3D por Kyttanen

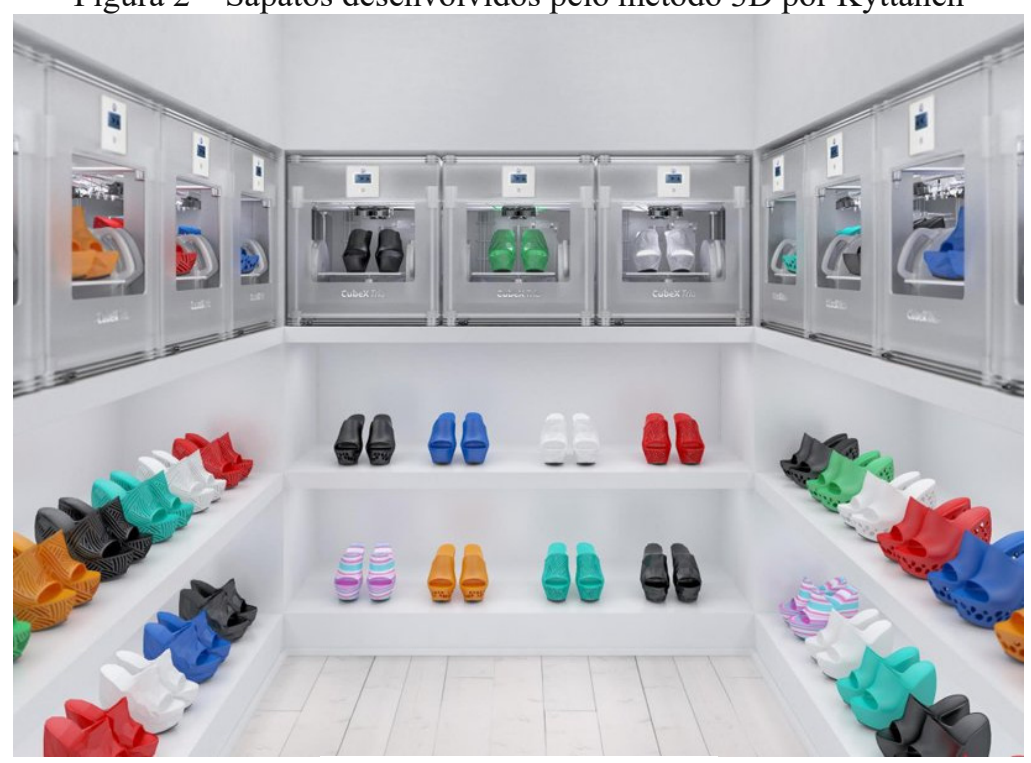

Fonte: Valentina Leva, 2013 
Em 2010 Iris Van Herpen, estilista holandesa, tornou-se a primeira pessoa a utilizar a impressão 3D em uma peça exibida nas passarelas do Amsterdam Fashion Week (figura 3) com a coleção Crystallization (KUHN e MINUZZI, 2015), apresentando ao público uma combinação entre a tecnologia da impressão $3 \mathrm{D}$ e os processos manuais e artesanais da alta costura.

Dentre os eventos de moda, o desfile é aquele que expõe, numa articulação de variados elementos, os conceitos trabalhados pelo criador ou pela marca. É uma função entre tempo e espaço que permite a apresentação dos produtos de forma lúdica, na tentativa de criar no espectador um sentimento de forte identificação com aquilo que vê (GRUBER e RECH, 2011, p. 109).

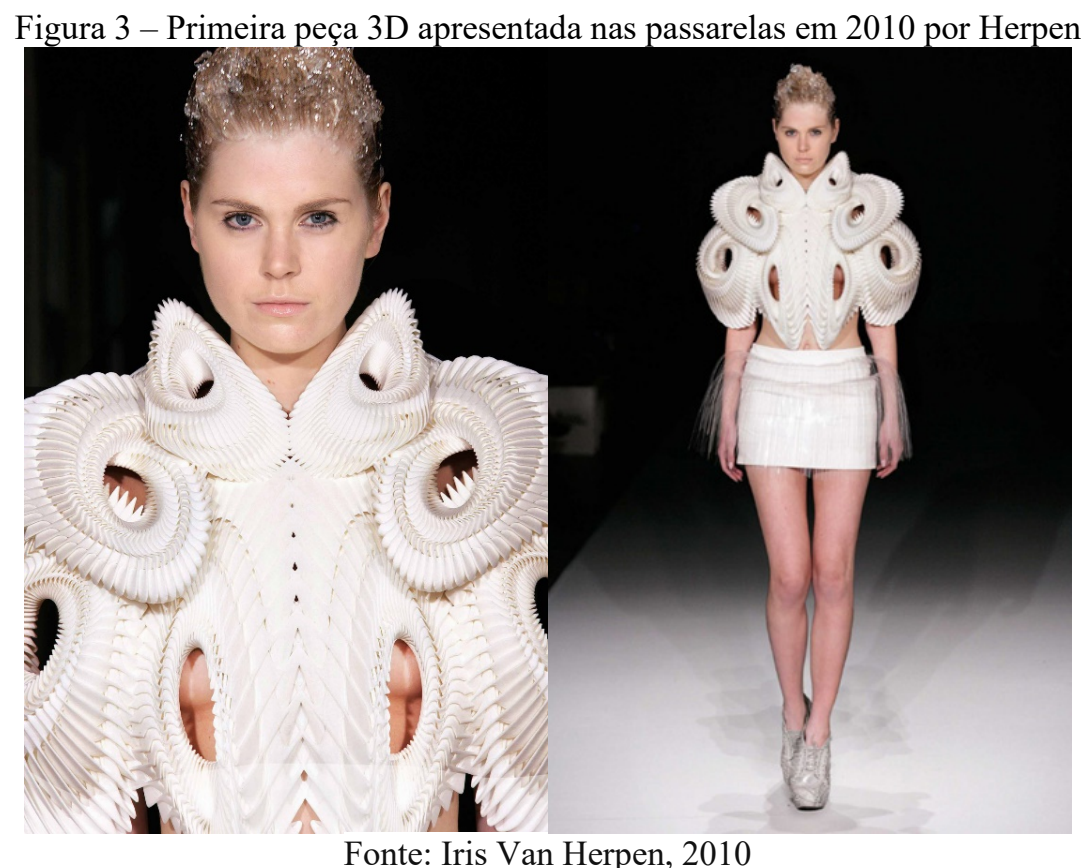

Em contrapartida ao Kyttanen, a notabilidade de Herpen se configurou com a apresentação de suas coleções em eventos de moda, desfiles, os quais servem para promover e divulgar a marca, atraindo também as mídias e possíveis consumidores, disseminando inovações e técnicas.

As peças de Van Herpen sustentam a afirmação de que moda é, sobretudo, arte, vide a exposição programada para 2021 de suas obras no Museu Les Arts Décoratifs, em Paris, voltado para as artes decorativas e design. O que não é novidade para quem tem personalidades como Björk, Tilda Swinton e Lady Gaga como manequins para o que cria (FRANK, 2020).

Assim, com criações conceituais e vanguardistas, Van Herpen consegue equilibrar moda, tecnologia, ciência, arte e design em suas composições, tornando-as singulares devido ao diferencial proporcionado pela impressão 3D as peças, exemplificada na figura abaixo (figura 4). Esse fator faz com que personalidades artísticas que frequentam e participam de grandes eventos como premiações, bailes, shows e performances utilizem suas produções. 
Figura 4 - Lady Gaga para o novo álbum “Chromatica” vestindo Herpen (2020)

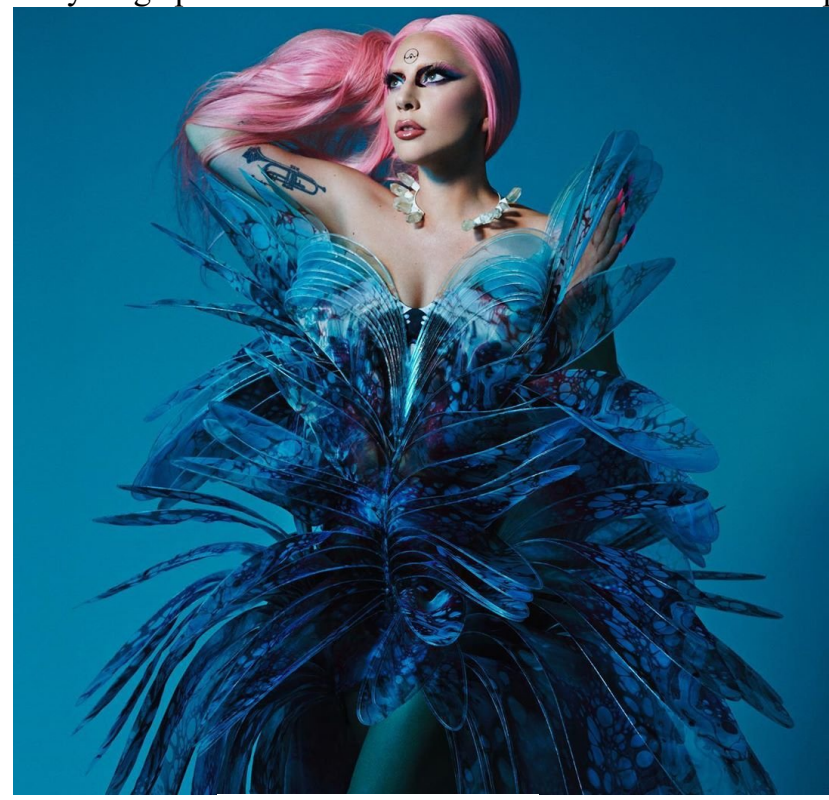

Fonte: Iris Van Herpen, 2020

No cenário brasileiro, o processo de manufatura aditiva também vem sendo desenvolvido. A grife mineira Plural exibiu uma coleção a partir da tecnologia na exposição "Minas +10" com intuito de apresentar as viabilidades as quais o método pode trazer para moda mineira.

Em parceria com o Serviço Nacional de Aprendizagem Industrial (SENAI) e outras instituições, a marca elaborou quatro peças por meio da técnica de Modelagem por Fusão e Deposição (FDM), no qual um filamento plástico é derretido para configurar maior flexibilidade para as composições (CONCEIÇÃO e SANTOS, 2017; IVO, 2017; RANGEL, 2017), algumas peças podem ser vistas na figura abaixo (figura 5).

Figura 5 - Looks 3D criados pela marca Plural em 2017

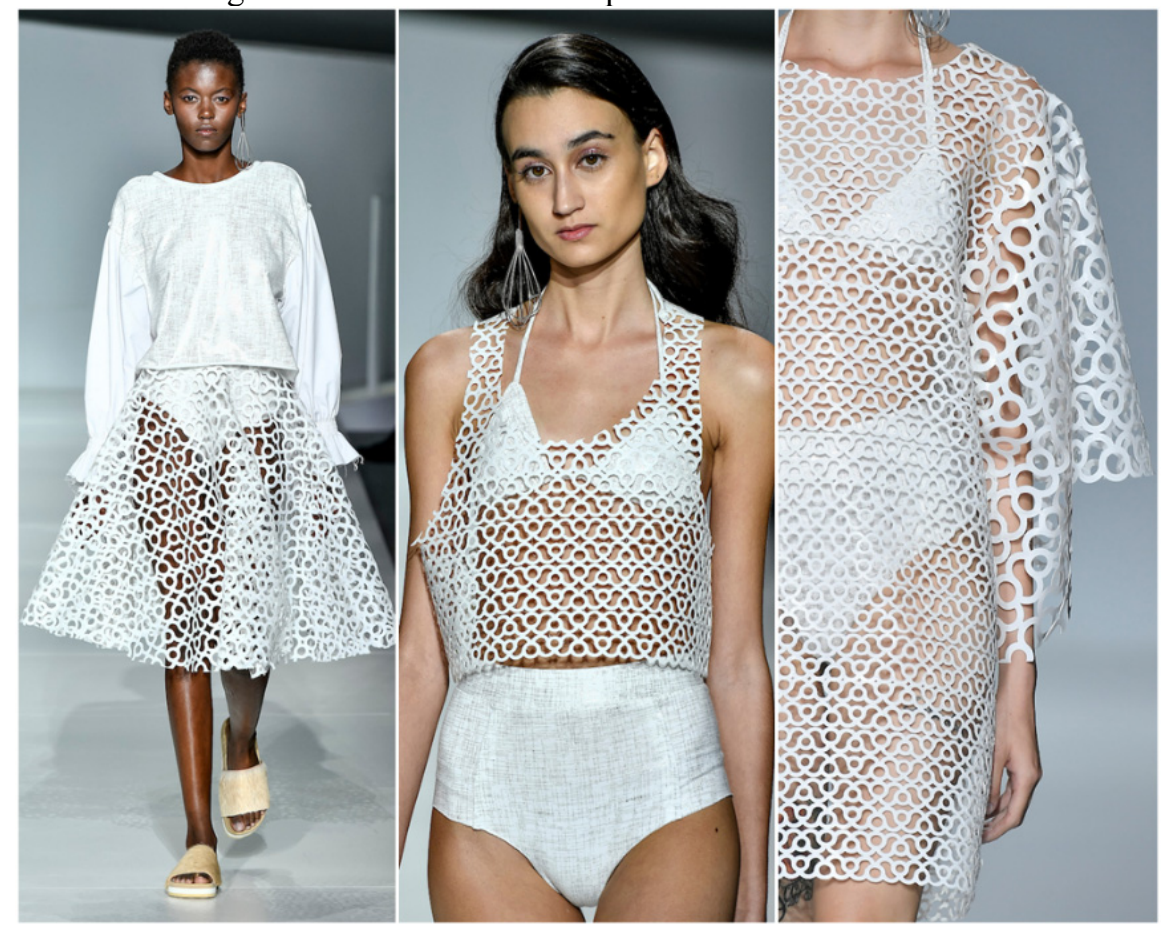

Fonte: Ludmilla Rangel, 2020 
No setor dos acessórios, a marca brasileira Yoface é a pioneira na produção de óculos por meio da impressão tridimensional. Com estilo vanguardista e minimalista, utilizam o Nylon em pó como matéria-prima sustentável. Fundamentado em práticas ecológicas, a grife procura oferecer itens leves, confortáveis e fashions aos clientes, trabalhando cada detalhe de forma customizada (ROSOLEN, 2020), algumas produções podem ser vistas abaixo (figura 6).

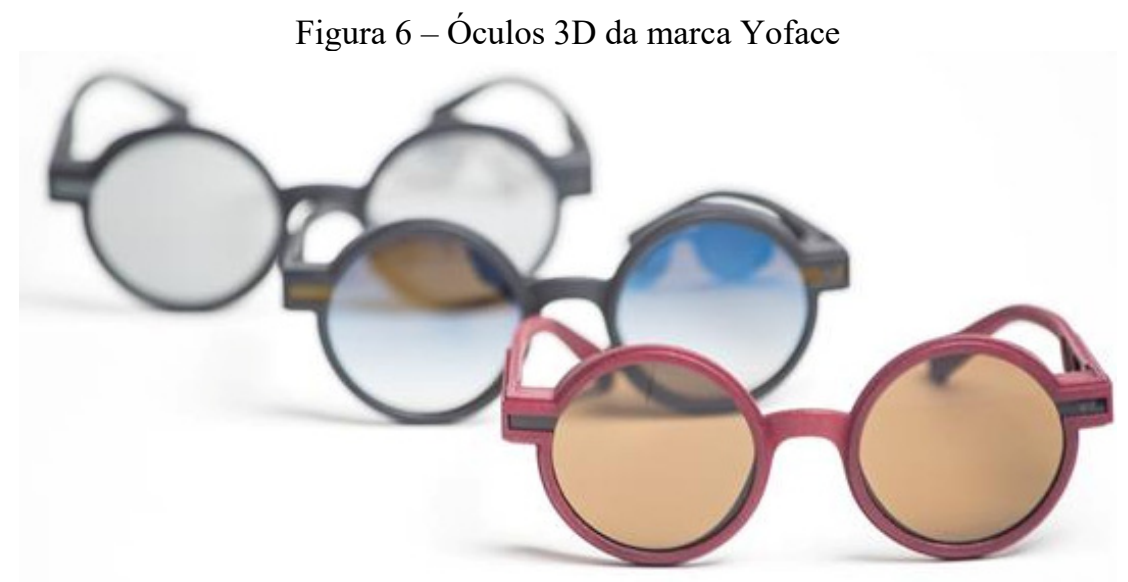

Fonte: Ilca Maria Estevão, 2019

\subsection{Desafios e reflexões}

Em busca de um consumo mais consciente, grupos de pessoas, têm cada vez mais exigido de empresas, principalmente no âmbito da moda, transparência na cadeia produtiva evidenciando e denunciando adversidades ainda persistentes nas produções (VALADARES, 2020; ZURI, 2016), como condições de trabalho forçado, crueldade animal, além da necessidade urgente de criação de alternativas sustentáveis e ecológicas de fabricação. Nesse sentido, a constatação dessas problemáticas são aspectos relevantes no processo decisório de compra de tais consumidores.

Os consumidores estão reavaliando suas prioridades e questionando o que eles acham que tem valor. No mundo da moda, o chamado "Novo Consumismo" se traduziu em demanda por maior transparência, autenticidade dos valores da marca, processos sustentáveis, economia de compartilhamento e experiências de varejo originais. É o momento de pensar em novas alternativas e rever antigos processos (CONCEIÇÃO e SANTOS, 2017, n.p).

Com isso, a produção a partir das impressoras 3D tem proporcionado um novo caminho para sustentabilidade, assim como Abreu e Menezes (2017) evidenciam, o processo de criação do projeto digital desencadeia diretamente no protótipo, sem fases intermediárias, sendo o desperdício de insumos menos intenso, utilizando somente o necessário para o desenvolvimento das peças.

No que diz respeito aos desdobramentos, levando em consideração um cenário em que grande parte da população teria condições de obter ou ter acesso a uma impressora $3 \mathrm{D}$, outros impasses devem ser considerados. Para Ramalho (2015, n.p), “a impressão 3D apresenta-se assim como uma potencialmente inesgotável fonte de possibilidades: de negócio, de criação, mas também de infração de direitos de propriedade intelectual".

Em outras palavras, dado a atual conjuntura da legislação brasileira promulgada em 1998, a qual regulariza os direitos autorais dentro do país, essa passou por poucas mudanças desde a sua implementação, onde as características de uma nova cultura, baseada na liberdade de criação e adaptação de projetos existentes, não são levadas em consideração (LINDNER, 2020) conferindo, assim, uma gama de possibilidades para plágios e cópias.

Isto é, as criações com base em arquivos digitais a fim de permitir a concretização do produto final colidem com a questão do direito autoral no contexto da produção descentralizada. O método de 
impressão tridimensional, dentro da cultura maker, permite a reprodução de quase todos os projetos 3D disponíveis digitalmente, uma vez que a Lei 9.610/1998, Lei de Direitos Autorais não está adaptada a esse tipo de produção fragmentada, viabilizando inúmeras violações (BOA IMPRESSÃO, 2019).

\begin{abstract}
A Lei $\mathrm{n}^{\circ}$ 9.610, de 1998, regula os direitos autorais no Brasil. São mais de 20 anos de consolidação e inúmeras práticas mudaram de lá para cá. Naquele período seria impossível imaginar a reprodução de capinhas de celulares, parafusos e até peças gigantescas por uma impressora 3D (BOA IMPRESSÃO, 2019).
\end{abstract}

Para corroborar com essa ideia, cabe também mencionar o Art. 7 da Lei 9.610 o qual expressa que: "São obras intelectuais protegidas as criações do espírito, expressas por qualquer meio ou fixadas em qualquer suporte, tangível ou intangível, conhecido ou que se invente no futuro [...]" (grifo nosso). Assis (2018) esclarece que tal passagem possibilita que qualquer elemento produzido pela manufatura aditiva, no presente momento ou em anos posteriores, será assegurado pela Lei de Direitos Autorais (LDA), independentemente da origem e finalidade produtiva.

Ademais, concomitantemente à desatualização da Lei 9.610, o Marco Civil da Internet, Lei 12.965/2014 que "Estabelece princípios, garantias, direitos e deveres para o uso da Internet no Brasil" também apresenta imprecisões na medida em que não confere limites acerca do que pode ou não ser elaborado com por meio da técnica.

Nesse segmento, se por um lado tem-se a impressão tridimensional como um recurso sustentável e prático, a qual permite a criação de artefatos decorativos e peças funcionais do vestuário, por outro, é notório observar que a pouca limitação desse método pode desencadear a elaboração de artigos nocivos à segurança da população. A exemplo tem-se a arma de fogo, "The Liberator" (figura 7), desenvolvida pelo americano Cody Wilson feita a partir da impressão tridimensional com plástico Acrilonitrila Butadieno Estireno (ABS), material flexível, resistente e leve, que a impedia de ser reconhecida por detectores de metal, o que suscitou debates quanto a falta de regras aplicadas a tecnologia 3D (DABAGUE, 2014).

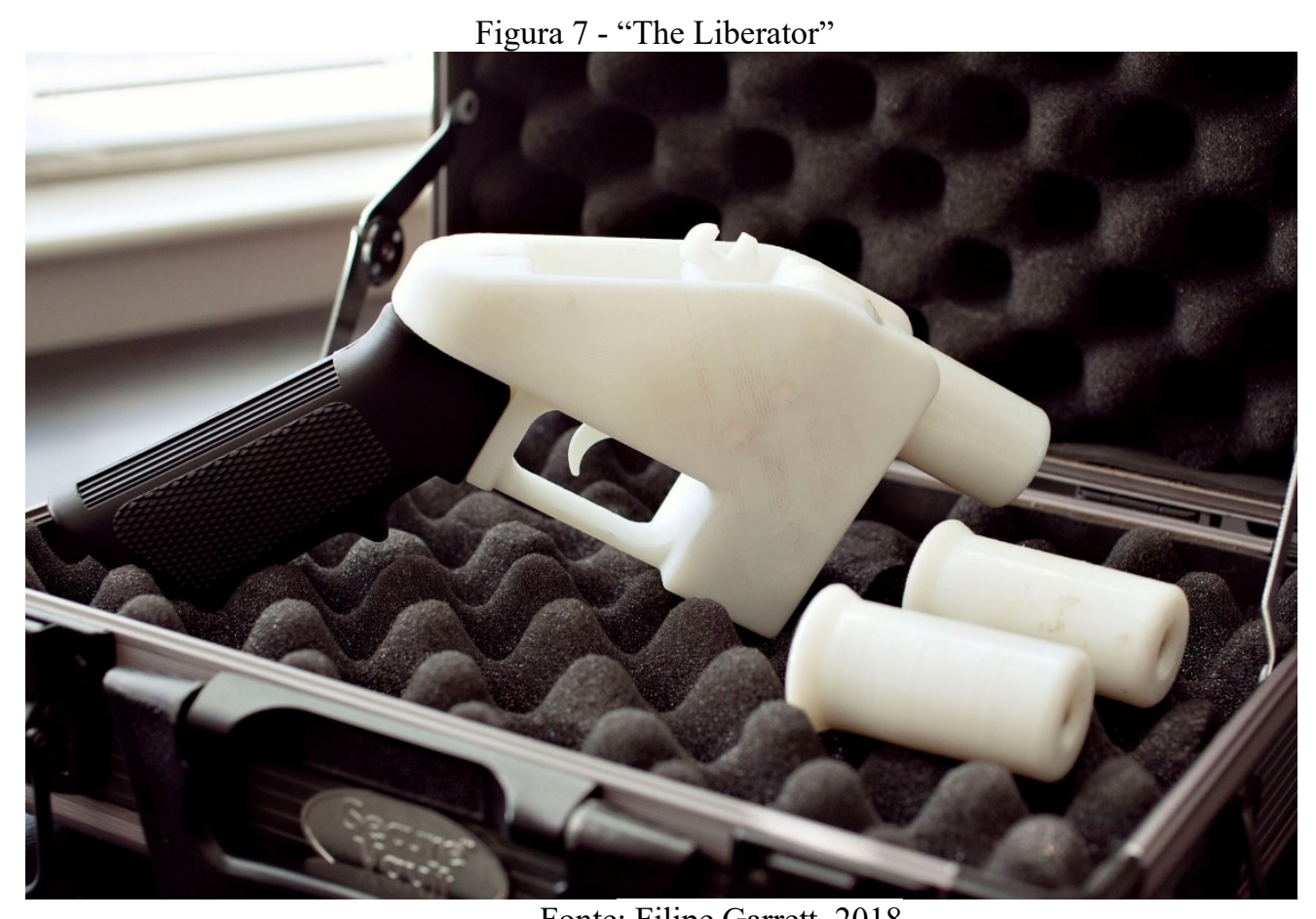

Fonte: Filipe Garrett, 2018

Gomes $(2015$, p. 31) afirma que "A enorme vantagem de impressão 3D é que não há complicações ou limitações em termos de tridimensionalidade ou complexidade, tudo que se possa imaginar é possível". Assim dizendo, além da insuficiência de barreiras legislativas, no campo prático 
as criações podem ser inúmeras, acarretando uma superprodução, o que contraria a própria premissa de sustentabilidade apresentada por aqueles que optam por esse meio de produção por ser menos agressivo ao meio ambiente.

Além disso, faz-se imperativo considerar que o descarte de lixo no país, principalmente do plástico, ainda é um problema recorrente no qual de acordo com dados da World Wide Fund for Nature (WWF), organização não governamental internacional que atua nas áreas da conservação, investigação e recuperação ambiental, o Brasil é o quarto país do mundo que mais gera lixo plástico.

Nesse sentido, o excesso produtivo a partir dessa tecnologia sem um local adequado de descarte e conscientização da população seria um fator adicional à destruição ambiental, considerando que o ciclo de vida desses produtos, devido ao principal material nas produções ser o plástico, utilizados nas fabricações 3D são curtos, caracterizando pouca durabilidade aos produtos, fazendo com que esses sejam descartados mais rapidamente.

A falta de um planejamento adequado para o descarte de lixo ainda é um dos principais problemas ambientais do Brasil. Mesmo após a instituição da Política Nacional de Resíduos Sólidos - PNRS existem ainda 3 mil lixões e aterros controlados espalhados no território nacional (VG RESÍDUOS, 2018).

Isto é, mesmo com a instituição da PNRS, Lei $\mathrm{n}^{\circ}$ 12.305/10, que estabelece a prática de costumes sustentáveis, descarte correto de resíduos sólidos e a atenuação e ressignificação na geração de lixo (BRASIL, 2010), o despojamento de produtos em áreas indevidas e ausência de medidas efetivas que priorizem a transformação em vez da rejeição imediata de detritos são adversidades recorrentes no país. Assim, demonstrando a necessidade de uma reeducação ambiental e social antes da introdução de itens advindos de novas práticas produtivas, as quais demandam o uso de elementos com características prejudicais ao ecossistema para fabricação.

Outro fator a se considerar é a descentralização do processo produtivo e a customização em massa em que o consumidor tem autonomia para personalizar e ainda fabricar o próprio produto, afetando dessa forma a distribuição de artefatos industriais. "Com a popularização e diversificação das impressoras 3D, qualquer um, quase não importando o lugar que se encontre, pode se tornar um fabricante" (MONTEIRO, 2015, p. 64).

Dessa forma, essa transposição produtiva exigirá inegavelmente novas formas de negócios, como Dabague (2014) apresenta, esse contexto de inovações tecnológicas nos meios produtivos provocará mudanças significativas na ordem econômica, refletindo também nos campos sociais, políticos e organizacionais.

Para além disso, outro aspecto relevante é a responsabilidade acerca dos produtos feitos por meio de arquivos disponibilizados digitalmente, uma vez que existem muitas possibilidades em relação à forma como o produto final será de fato concretizado. Isto é, o consumidor poderá imprimir o objeto em uma impressora 3D própria ou adquirir o item digital e imprimi-lo em um local específico, evidenciando indagações em relação a imprecisões e mau funcionamento do produto.

Castanheira, especialista em direito digital, ressalta que a tecnologia ainda gera debates conflituosos no Brasil "O assunto provoca controvérsia. Por exemplo: de quem é a responsabilidade de consertar uma peça defeituosa que foi impressa, da empresa que realizou a impressão ou do designer que elaborou o arquivo?" (LINDNER, 2020), melhor dizendo, onde ou com quem o usuário poderia recorrer a respeito destas questões são perguntas em aberto.

$\mathrm{Na}$ moda, em paralelo as contribuições e inovações possibilitadas pela manufatura aditiva a marcas de luxo, tem-se as roupas, predominantemente, como um reforço das desigualdades sociais dentro do contexto da quarta revolução industrial, na qual "a indústria tende a ser totalmente automatizada a partir de sistemas que combinam máquinas com processos digitais" (ORTEGA, 2019).

Tendo em vista que o Brasil é o sétimo país mais desigual do mundo de acordo com dados do Programa das Nações Unidas para o Desenvolvimento (PNUD), no qual o rendimento mensal dos $1 \%$ mais ricos do país é quase 34 vezes maior do que o rendimento da metade mais pobre da população, segundo a divulgação dos dados pelo Instituto Brasileiro de Geografia e Estatística (IBGE) (FORTE, 2020), o acesso a esse meio de produção será direcionado aos que possuem uma condição financeira 
elevada. Sendo assim, a tendência do uso das impressoras 3D e dos produtos feitos a partir dessa técnica no país é crescer, mas para aqueles com condições de alcançar e acompanhar as revoluções tecnológicas (COGRA, 2020).

Dessa forma, analisando historicamente o desenvolvimento da indumentária é notório perceber que o vestuário se configurou ao longo da história como uma forma de distinção social entre ricos e pobres, acentuando a lacuna existente entre as classes.

A indumentária sempre serviu como signo de diferenciação entre as classes sociais. Nobres vestiam roupas caras, com qualidade superior e durabilidade maior, enquanto as classes menos privilegiadas usavam trajes simples, sem cor, produzidos com tecidos ásperos e de forma caseira (CARACIOLA, 2018, p. 82).

Com isso, apesar das criações como as de Herpen e até mesmo de marcas de acessórios nacionais que fazem uso do método 3D terem um segmento de mercado estabelecido como de luxo, a moda como um objeto de comunicação social e cultural, sendo utilizada como forma de expressão e reforço do pensamento crítico, deve dialogar também com aqueles que se encontram além da parcela detentora das riquezas.

A alta-costura é feita para um público exclusivíssimo, que pode gastar a partir de US\$ 10 mil numa peça exclusiva, totalmente artesanal e produzida com os materiais e tecidos mais preciosos. Ainda que tenha consumo restrito, a chamada 'haute couture' é um laboratório criativo inestimável para as grandes grifes. Esse segmento é onde os estilistas desenvolvem ideias únicas, que poderão ser trabalhadas de forma comercial no futuro (MORAIS, 2016).

Isto é, a moda, composta por peças, acessórios e inovações tecnológicas no cenário brasileiro é raramente ofertada de forma democrática. Assim, priorizando aqueles que consomem marcas, tendências e itens do vestuário, muitas vezes, por status, reafirmando uma posição social, sendo os desfiles, dentre os variados eventos de moda, ambientes que reafirmam essa estratificação social existente no país.

Em virtude do público que comparece e consome esses produtos, frequentemente caracterizado por convidados famosos e personalidades midiáticas de prestígio, restringe-se o acesso popular a essas produções e novidades, como a manufatura aditiva.

Dessa maneira, como as poucas marcas de moda brasileira as quais trabalham com a tecnologia tridimensional são definidas pela opulência, uma parte consideravelmente pequena da população terá contato e condições de obtê-las, impedindo que a moda como forma de expressão crítica, social, cultural alcance as grandes massas.

\section{Conclusão}

Mediante a metodologia de caráter exploratório foi possível promover a aproximação e a investigação de prováveis desdobramentos sob viés social, legal, mercadológico e sustentável da manufatura aditiva. Tal convergência permitiu a averiguação da tecnologia dentro de tendências benéficas e maléficas. As contribuições criadas pela impressão 3D em níveis práticos, produtivos, experimentais e funcionais são inegáveis, dado as oportunidades de criação, como a automação do processo produtivo no setor da moda excluindo as chances da utilização de mão de obra análoga a escrava.

Todavia, os desdobramentos desse sistema são, na mesma medida, incontestáveis. Dessa forma, foi explicitado como e quais esferas podem ser afetadas pela produção tridimensional, sendo o âmbito social o destaque dado às características que compõe a sociedade contemporânea brasileira. À vista disso, delineou-se também as produções de moda dentro do contexto da indústria 4.0 como forma de acentuar as desigualdades sociais, uma vez que o vestuário ao longo da história se firmou como uma forma de distinção de classe.

A presente pesquisa enfatiza e evidencia a necessidade de atualização das leis dentro da conjuntura da quarta revolução industrial, estabelecendo limites de criação e de direitos autorais, 
advertindo também a indispensabilidade da conscientização popular a respeito da superprodução e descarte indevido, motivado pelo ciclo de vida curto dos produtos provenientes desse método.

Nesse sentido, destaca-se também como a utilização da tecnologia na indústria fashion pode ser uma estratégia de marketing para atrair consumidores conscientes que buscam uma produção mais responsável, não obstante negligenciando os impactos consideráveis trazidos pelo novo modo de fabricação, uma vez que os componentes, apesar de serem de variados materiais, são sobretudo plásticos, recursos não renováveis que desencadeiam, devido à utilização desenfreada, o esgotamento de fontes naturais.

Desse modo, foi possível inferir que o acesso à manufatura aditiva, principalmente nas fabricações de vestuário, será voltada a um grupo de pessoas abastadas, dadas as produções exuberantes e luxuosas com preços elevados feitas por grifes, as quais não alcançam um grande número de pessoas.

Ao propor uma reflexão sobre esses fatores, nota-se que as composições de moda por meio da impressão 3D reforçam um contraste social por anos enraizado na sociedade. Assim, a indispensabilidade de avaliar a moda para além da estética é de suma importância para que as suas manifestações artísticas, críticas, sociais e culturais intrínsecas possam dialogar com o contexto e com as pessoas que formam a sociedade, abrangendo diferentes posições sociais em oposição ao distanciamento entre elas.

\section{D Printing in fashion: challenges and reflections}

Abstract: As a driving force of the fourth industrial revolution, 3D printing is constantly praised for providing innovating contributions to the productive process. However, the impacts of this technology are still under little evaluation and debate. In this sense, with the intent of analyzing, reflecting and fathoming the possible effects of this technique in the fashion segment, a bibliographic research is conducted in an exploratory manner with the objective of contextualizing the technique in the fashion sector, as well as addressing some of its developments concerning its social, marketing, sustainability and legal aspects.

Keywords: Fashion; 3D Printing; Social impacts; Sustainability; Copyrights

\section{Referências bibliográficas}

ABREU, Ana C.; MENEZES, Marizilda S. Impressão 3D: considerações sobre o futuro impacto na área da moda. In: $13^{\circ}$ COLÓQUIO DE MODA, 2017, São Paulo. Anais eletrônicos... Disponível em: <http://www.coloquiomoda.com.br/anais/Coloquio\%20de\%20Moda\%20\%202017/COM_ORAL/co_5/co_5_IMPRESSAO_3D_\%20CONSIDERACOES.pdf >. Acesso em: 7 jul. 2020.

ASSIS, Marley A. P. Impressão 3D, modelos de negócios e os novos cenários para a propriedade intelectual. 2018. 124 f. Dissertação (Mestrado Profissional em inovação Tecnológica e Propriedade Intelectual) - Universidade Federal de Minas Gerais, Instituto de Ciências Biológicas, Belo Horizonte, 2018. Disponível em: <https://repositorio.ufmg.br/bitstream/1843/BUOSB7MKRT/1/disserta_o_marley.pdf>. Acesso em: 6 jul. 2020.

BRASIL. Lei no 9.610, de 19 de fevereiro de 1998. Altera, atualiza e consolida a legislação sobre direitos autorais e dá outras providências. Disponível em: <http://www.planalto.gov.br/ccivil_03/leis/l9610.htm>. Acesso em: 8 jul. 2020.

BRASIL. Lei no 12.965, de 23 de abril de 2014. Estabelece princípios, garantias, direitos e deveres para o uso da Internet no Brasil. Disponível em: <http://www.planalto.gov.br/ccivil_03/_ato2011-2014/2014/lei//12965.htm>. Acesso em: 8 Jul. 2020. 
BRASIL. Lei no 12.305, de 2 de agosto de 2010. Institui a Política Nacional de Resíduos

Sólidos; altera a Lei n 9.605, de 12 de fevereiro de 1998; e dá outras

providências. Disponível em: <http://www.planalto.gov.br/ccivil_03/_ato2007-

2010/2010/lei/l12305.htm >. Acesso em: 13 ago. 2020.

BRASIL é o $4^{\circ}$ país do mundo que mais gera lixo plástico. World Wide Fund for Nature Brasil, 2019. Disponível em: <https://www.wwf.org.br/?70222/Brasil-e-o-4-pais-do-mundo-que-mais-geralixo-plastico>. Acesso em: 11 jul. 2020.

CARACIOLA, Carolina B. A Influência da Moda na Sociedade Contemporânea. Arquivos do CMD, São Paulo, v. 7, n. 2, p.79-93, 12 ago. 2019. Disponível

em: <https://periodicos.unb.br/index.php/CMD/article/view/22220/23287 >. Acesso em: 11 jul. 2020.

CONCEIÇÃO, Maria E. J.; SANTOS, Jorge R. L. Remodelando o Design do Vestuário com tecnologias digitais de produção. Revista Tríades, Rio de Janeiro, v. 6, n. 1, 2017. Disponível em: <https://triades.emnuvens.com.br/triades/article/view/95/57>. Acesso em: 6 jul. 2020.

DABAGUE, Leonardo A. M. O processo de inovação no segmento de impressoras 3d. 2014. 51 f. Monografia (Bacharelado apresentado ao Curso de Ciências Econômicas, Setor de Ciências Sociais Aplicadas) - Universidade Federal do Paraná, Curitiba, 2014. Disponível

em: <https://acervodigital.ufpr.br/bitstream/handle/1884/37115/MONOGRAFIA19-2014-

1.pdf?sequence=1\&isAllowed=y>. Acesso em: 7 jul. 2020.

ESTEVÃO, Ilca M. Conheça a primeira marca brasileira a imprimir óculos em 3D. Metrópoles, 2019. Disponível em: <https://www.metropoles.com/colunas-blogs/ilca-maria-estevao/conheca-aprimeira-marca-brasileira-a-imprimir-oculos-em-3d>. Acesso em: 12 ago. 2020.

FRANK, Gustavo. Exoesqueletos, 3D e ilusão de ótica: Iris Van Herpen cria o futuro da moda. Uol, 2020. Disponível em: <https://www.uol.com.br/nossa/noticias/redacao/2020/04/22/ohipnotismo-da-biologia-cria-nova-vida-a-moda-nas-maos-de-iris-van-herpen.htm>. Acesso em: 14 ago. 2020.

FORTE, Bárbara. Por que Brasil é o sétimo país mais desigual do mundo. Uol, 2020. Disponível em: <https://www.uol.com.br/ecoa/ultimas-noticias/2020/02/20/por-que-brasil-e-o-setimo-pais-maisdesigual-do-mundo.htm>. Acesso em: 8 jul. 2020.

GARRETT, Filipe. Impressora 3D pode criar armas?: veja perguntas e respostas sobre o tema. TechTudo, 2020. Disponível em: <https://www.techtudo.com.br/listas/2018/08/impressora-3dpode-criar-armas-veja-perguntas-e-respostas-sobre-o-tema.ghtml>. Acesso em: 12 ago. 2020.

GOMES, Anabela B. Tecnologia na Moda: o futuro da impressão $3 \mathrm{~d}$ e a sustentabilidade na moda. 2015. 49 f. Dissertação (Mestrado em Design de Moda) - Faculdade de Engenharias Departamento de Ciência e Tecnologia Têxteis, Universidade da Beira Interior, Covilhã, 2015. Disponível em: <https://ubibliorum.ubi.pt/bitstream/10400.6/5947/1/4506_8719.pdf>. Acesso em: 6 jul. 2020.

GRUBER, Crislaine.; RECH, Sandra R. Intersecções entre moda e espetáculo: um estudo acerca do desfile de moda. ModaPalavra e-periódico, Florianópolis, v. 4, n. 7, p. 108-126, 2011. Disponível em: <http://www.revistas.udesc.br/index.php/modapalavra/article/view/7915/5453>. Acesso em: 7 jul. 2020.

HESS, Francieli. Movimento Maker: a nova revolução tecnológica está em nossas mãos. Fashion Bublbes, 2020. Disponível em: <https://www.fashionbubbles.com/trabalhosartesanais/movimento-maker-nova-revolucao-tecnologica-em-nossas-maos/>. Acesso em: 11 jul. 2020.

HERPEN, Iris V. Iris Van Herpen, 2020. Disponível em: <https://www.irisvanherpen.com/hautecouture/crystallization>. Acesso em: 10 jul. 2020.

HERPEN, Iris V. Iris Van Herpen, 2020. Disponível em: <https://www.irisvanherpen.com/>. Acesso em: 13. Ago. 2020. 
IVO, Flávia. Tecidos feitos em 3D surpreendem visitantes do Minas Trend. Hoje em dia, 2017. Disponível em: <https://www.hojeemdia.com.br/mais/tecidos-feitos-em-impressoras-3dsurpreendem-visitantes-do-minas-trend-veja-as-fotos-1.456866>. Acesso em: 30 jun. 2020.

JUNIOR, Natal A. C.; CASTILLO, Leonardo G. Impressão 3D na cultura do design contemporâneo. In: $11^{\circ}$ Congresso Brasileiro de Pesquisa e Desenvolvimento em Design, 2014, Gramado. Disponível em: <http://www.ufrgs.br/ped2014/trabalhos/trabalhos/523_arq2.pdf>. Acesso em: 11 jul. 2020.

KUHN, Renato.; MINUZZI, Reinilda F. B. In: Panorama da impressão 3D no design de moda. Moda documentada: Museu, Memória e Design, São Paulo: Estação das Letras e Cores, v. 1, n. 1, 2015. Disponível em: <http://www.modadocumenta.com.br/anais/anais/5-Moda-Documenta-2015/02Sessao-Tematica-Design-Moda-e-Cultura-Digital/Renato-Kuhn_ModaDocumenta2015_PANORAMA-DAIMPRESSA_O-3D-NO-DESIGN-DE-MODA.pdf>. Acesso em: 29 jun. 2020.

KOTLER, Philip.; KELLER, Kevin L. Administração de marketing. Tradução de Sônia Midori Yamamoto, 14º Edição. São Paulo: Pearson Education do Brasil, 2012.

LEVA, Valentina. Fashion design revolution: 3D printed shoes by Janne Kyttanen. Archilovers, 2013. Disponível em: <https://www.archilovers.com/stories/4265/fashion-design-revolution-3d-printed-shoes-by-jannekyttanen.html>. Acesso em: 13 jul. 2020.

LINDNER, Julia. Dá para imprimir. Mas e o direito autoral?. Estadão. Disponível em: <https://infograficos.estadao.com.br/focas/movimento-maker/da-para-imprimir-mas-e-o-direitoautoral.php>. Acesso em: 10 jul. 2020.

MARTINS, Vítor H. C. Impressão 3D: uma abordagem de produção mais limpa?. Dissertação de Mestrado. Minho, 2017.

MONTEIRO, Marco T. F. A Impressão 3d no meio produtivo e o design: um estudo na fabricação de joias. 2015. 129 f. Dissertação (Mestrado) - Escola de Design da Universidade do Estado de Minas Gerais, Belo Horizonte, 2014. Disponível em: <http://anapaulanasta.com/wpcontent/uploads/2015/09/Disserta\%C3\%A7\%C3\%A3o-Marco-T\%C3\%BAlio-Ferreira-Monteiro.pdf>. Acesso em: 6 jun. 2020.

MORAIS, Deborah. Iris Van Herpen e a alta costura pós-moderna. Jardin, 2016. Disponível em: <https://use-jardin.com.br/iris-van-herpen-alta-costura-pos-moderna/>. Acesso em: 8 jul. 2020.

MOREIRA, Daniela. Pequenos podem lucrar com a impressão 3D. Exame, 2011. Disponível em: <https://exame.com/pme/pequenos-podem-lucrar-com-impressao-3d/>. Acesso em: 6 ago. 2020.

O que devemos saber sobre impressão 3D e direitos autorais?. Boa Impressão, 2019. Disponível em: <https://boaimpressao3d.com.br/dicas/impressao-3d-e-direitos-autorais/>. Acesso em: 7 jul. 2020.

ORTEGA, João. Indústria 4.0: entenda o que é a quarta revolução industrial. StarSe, 2019. Disponível em: <https://www.startse.com/noticia/nova-economia/industria-4-0-entenda-o-que-equarta-revolucao-industrial>. Acesso em: 11 jul. 2020.

QUAL a realidade do descarte de lixo nas cidades brasileiras? Vg Resíduos, 2018. Disponível em: <https://www.vgresiduos.com.br/blog/qual-a-realidade-do-descarte-de-lixo-nas-cidadesbrasileiras/>. Acesso em: 8 jul. 2020.

RAMALHO, Ana. Impressão 3D, direitos de autor e outros direitos de propriedade intelectual. Revista de Direito Intelectual, n. 2, 2015. Disponível em: <https://www.researchgate.net/profile/Ana_Ramalho/publication/285593392_3D_Printing_Copyright_ and_Other_Intellectual_Property_Rights_in_Portuguese/links/568a381b08ae051f9afa3592/3DPrinting-Copyright-and-Other-Intellectual-Property-Rights-in-Portuguese.pdf>. Acesso em: 7 jul. 2020.

RANGEL, Ludmilla. Plural desenvolve roupas em 3D!. Fashionistando, 2017. Disponível em: <https://fashionistando.uai.com.br/minas-trend-plural-desenvolve-roupas-em-3d/>. Acesso em: 10 jul. 2020. 
REITER, Robyn. 10 Gorgeous Dresses Created With 3D Printing. Scribol, 2013. Disponível em: $<$ https://new.scribol.com/art-and-design/fashion/10-gorgeous-3d-printed-dresses/5/>. Acesso em: 11 jul. 2020.

ROSOLEN, Dani. A Yoface fabrica óculos com tecnologia de impressão 3D. Projeto Draft, 2020. Disponível em: <https://www.projetodraft.com/a-yoface-fabrica-oculos-com-tecnologia-de-impressao3d/>. Acesso em: 30 jun. 2020.

SANTOS, Beatrice P. et al. Indústria 4.0: desafios e oportunidades. Revista Produção e Desenvolvimento, v. 4, n. 1, p. 111-124, 2018.

TENDÊNCIAS do mercado de impressão para 2020. Cogra, 2020. Disponível em: <https://cogra.blog/2020/01/17/tendencias-do-mercado-de-impressao-para-2020/>. Acesso em: 14 jul. 2020.

The Boston Consulting Group. Embracing Industry 4.0 and Rediscovering Growth. Boston, 2015. Disponível em: <https://www.bcg.com/capabilities/operations/embracing-industry-4.0rediscovering-growth.aspx>. Acesso em: 4 mar. 2019.

VALADARES, Dandara. Escravidão nada moderna: como a moda pode combater o trabalho escravo. Carta Capital, 2020. Disponível em: <https://www.cartacapital.com.br/blogs/fashionrevolution/escravidao-nada-moderna-como-a-moda-pode-ajudar-a-combater-o-trabalho-escravo/>. Acesso em: 11 ago. 2020.

VICENTE, Catarina L. 0 design de calçado e a impressão 3D. 2016. 81 f. Dissertação (Mestrado em Design de Moda) - Universidade da Beira Interior, Faculdade de Engenharias, Departamento de Ciência e Tecnologia Têxteis, Covilhã, 2016. Disponível em: <https://ubibliorum.ubi.pt/bitstream/10400.6/5812/1/4863_9665.pdf>. Acesso em: 11 jul. 2020.

VOLPATO, Neri. et al. Prototipagem rápida: tecnologias e aplicações. $1^{\circ}$ Edição. São Paulo: Editora Blucher, 2007.

ZURI, Gabriela. A indústria das peles de animais, o sofrimento e a moda. Follow de Colours, 2016. Disponível em: <https://followthecolours.com.br/style/a-industria-das-peles-de-animais-osofrimento-e-a-moda/>. Acesso em: 13 jul. 2020. 